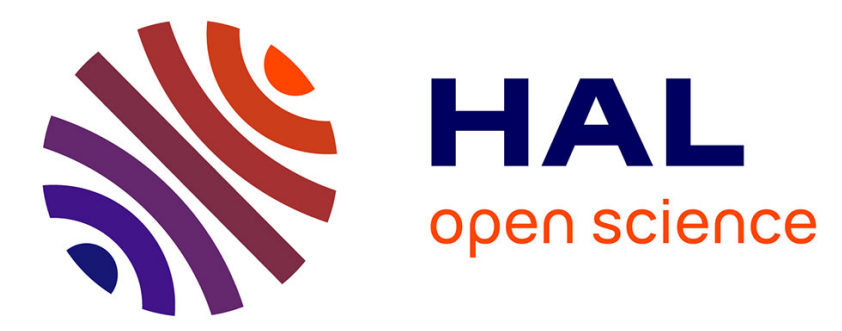

\title{
An E-banking platform for collaborative work between Education, Industry and Research
}

\author{
Marc Pasquet, Vincent Alimi, Sylvain Vernois, Christophe Rosenberger
}

\section{To cite this version:}

Marc Pasquet, Vincent Alimi, Sylvain Vernois, Christophe Rosenberger. An E-banking platform for collaborative work between Education, Industry and Research. International Symposium on Collaborative Technologies and Systems (CTS), May 2008, United States. pp.1-7. hal-00277651

\section{HAL Id: hal-00277651 \\ https://hal.science/hal-00277651}

Submitted on 6 May 2008

HAL is a multi-disciplinary open access archive for the deposit and dissemination of scientific research documents, whether they are published or not. The documents may come from teaching and research institutions in France or abroad, or from public or private research centers.
L'archive ouverte pluridisciplinaire HAL, est destinée au dépôt et à la diffusion de documents scientifiques de niveau recherche, publiés ou non, émanant des établissements d'enseignement et de recherche français ou étrangers, des laboratoires publics ou privés. 


\title{
An E-banking platform for collaborative work between Education, Industry and Research
}

\author{
Marc Pasquet $^{1}$, Vincent Alimi ${ }^{2}$, Sylvain Vernois ${ }^{1}$, Christophe Rosenberger ${ }^{1}$ \\ ${ }^{1}$ Laboratoire GREYC: ENSICAEN - Université de CAEN - CNRS \\ ${ }^{2}$ DRI (Department of Industrial Relationships): ENSICAEN \\ marc.pasquet@ensicaen.fr \\ vincent.alimi@ensicaen.fr \\ sylvain.vernois@ensicaen.fr \\ christophe.rosenberger@ensicaen.fr
}

\begin{abstract}
We present in this paper an e-banking platform used as a collaboration tool between more than 15 industrial companies, a school of engineering and different research laboratories. The main objective of this collaboration is to prepare the new e-banking protocols that will take place into the SEPA program (Single Euro Payments Area). This program has for objective to harmonize bank payment systems in Europe. It began to take effect in January 2008 and will continue through 2010. Many engineers have to be trained, lots of tests have to be realized from end to end in the e-banking chain with new protocols and recent research developments have to be integrated. Some quantitative results show the interest of this platform for all the partners.
\end{abstract}

KEYWORDS: E-Commerce, Collaborative Enterprise Security \& Access Control, Human-machine Collaborative Interaction.

\section{INTRODUCTION}

E-banking is one of the most challenging tasks in computer science for many reasons. First, the number of end-users of this complex system is extremely high as epayment concerns the whole world. Second, financial transactions must be as secure as possible to limit frauds while providing a fast service to users. Finally, the banking infrastructure involves many different technologies in electronics (smartcards, payment terminal) and IT (server, networks...).

We can also identify many problems that limit some new developments and evolutions in the e-banking domain. The industrial community in this area - banks, smartcards manufacturers... - is not very accessible. Each manufacturer of an e-banking component has a partial knowledge on the global chain. As a result it does not facilitate the global evolution of the e-banking chain to meet the SEPA program requirements (Single Euro Payments Area) [13]. These industrial companies are also reluctant to give some information on their product considering the security issues that are very important. That yields to a long duration training of recent employees. Another concern would be the difficult collaboration with research laboratories. For example, the DES (Data Encryption Standard) algorithm is still in use to secure e-banking messages even though it has been broken up in 1997 [6]. There is a long period between research developments and their real application in an ebanking chain. Last, there are few training degrees in the e-banking area while many companies need to recruit some technicians and engineers in this field. For example, in France, only one school of engineering delivers a degree in the e-banking area. Each year, at the ENSICAEN graduate school of engineering, nearly 80 students graduate with a master's degree in the e-banking field while 300 positions in this area are actually available.

For all these reasons, we are convinced that the collaboration between training, industry and research could provide lots of improvements in the banking area. We think that an e-banking platform could be a very attractive tool to make these three partners collaborate together (see Figure 1).

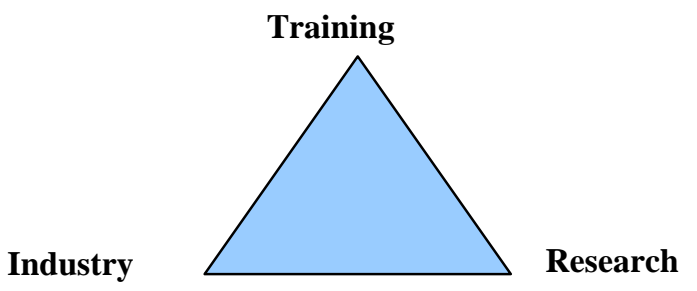

Figure 1. Collaboration in the e-banking area 
Industrial companies could recruit qualified employees, could integrate new solutions and test them in real conditions. A training school could propose many applied lectures and projects in the e-banking area while involving industrials in the student's training. Research laboratories would have the possibility to apply their works in a real context and would permit a high level of teaching for students.

This paper is organized as follows. Section 2 presents the e-banking platform we designed in collaboration with industrial companies, researchers and for training. Section 3 illustrates the benefits of such a collaboration for each actor. Section 4 gives some conclusions and perspectives of this work.

\section{E-BANKING PLATFORM}

In this section, we present the e-banking platform we designed that is to our knowledge unique in the world for the collaboration of the three types of partners. There are very few complete platforms to study end to end electronic payment transactions. The only existing complete electronic payment platforms, dedicated to internal teaching and researching, belong to the major banks and the card schemes (Visa and MasterCard). The R\&D laboratories have often worked on this part but generally processed with simulators and rarely with industrial products. The problem, in that case, is that there can be a big gap between a real platform and a simulator, mainly regarding the treatment of errors. Why? Because, in the electronic payment treatments, the errors are interpreted to create as few cancellation cases as possible and are analyzed by both involved banks (issuer and acquirer) through exceptions processing modules to have the lowest possible impact for the cardholder. If it is quite easy to develop a simulator to treat good transactions, it is very expensive to implement all the possible cases of errors in that simulator.

So, implementing an electronic payment platform composed of powerful industrial systems where two banks are able to exchange authorizations, clearing and settlement and where a cardholder and his card issued by a bank can withdraw money in another bank and has his account debited of the correct amount, appears clearly interesting for the following reasons:

- this platform constitutes a tool used by very high level trainings ;

- the use of industrial products permit to have operational engineers when they are recruited ;

- it is also capable to generate research activities on the hardware and software aspects in the electronic payment field ;
- this platform allows to study the effects of realistic errors,

- it makes possible to realize lots of interesting evolutions on the equipments, protocols and exchanges on real industrial products and analyzed the effects of these evolutions.

\section{Towards a generic payment system}

Our model of a generic payment system (see Figure 2) consists in a customer and a merchant exchanging money for goods and at least one financial institution making electronic payments into transfers of "real money" [1]. The customer and the merchant are linked to their banks (issuing bank and acquiring bank, respectively). During a transaction, the connectivity between the two banks is realized through card schemes or national operators.

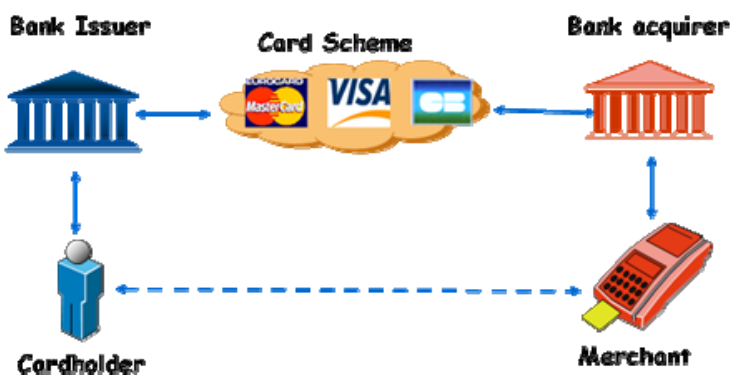

Figure 2. Model of a generic payment system

To answer those needs, the platform is dedicated to cover the whole market.

This chain involves:

- smart cards or any other devices used to identify the user;

- terminals used as a point of interaction;

- the use of communicating devices and distant computer systems exchanging secure information via heterogeneous communication and transport networks;

- computers and software required to treat, in real time, the authorization and the transaction (Front End). Those devices embed software to enable the confidentiality and the integrity of transferred data. The Front End is directly connected to a HSM (Hardware Security Module), material and software security elements, handling the identification/authentication of connected users.

In addition to all that devices directly implied in real time exchanges, an electronic payment chain requires 
hardware devices and software developments (Back End) in order to allow:

- the traceability of exchange as well as the archiving of proof, hence guaranteeing security $[9,10]$;

- the clearing and the settlement of that financial transaction ;

- the management of contracts (cardholder and merchant) ;

- the card issuing management process ;

- the treatment of the transaction before sending to the bank Information System.

The e-payment chain is completed by:

- a card personalization chain which allows a blank card to be personalized for a given cardholder and bank ;

- a part of the bank Information System.

The generic platform is constituted of two banks, each equipped with ATM (Automatic Teller Machine) and POS (Point Of Sale) which constitutes the Points of Interaction for users, a Front End, a Back End, some HSM, an Information System and an issuing system to personalize EMV (Eurocard, MasterCard, Visa, standard for banking smart cards) cards for the cardholders. The diagram of such a platform is described in the figure 3 .

Two industrial equipments are very difficult to implement in that platform:

- the authorization network because the real one cannot be accessible without great perturbations. False transactions cannot easily be removed ;

- the clearing and settlement network for the same reasons.

So, for these two equipments, indicated as card schemes on the diagram figure 4 , simulators can be used. The implementation of this platform, has started in 2004, and has associated from the beginning, the industrial companies, the teaching team, the students of the school and researchers.

The development of an industrial platform for electronic payment purpose requests to have a precise knowledge of the processes and functions that should be implemented. This is why one of the important points was the recruitment by the school of specialists, coming from the industrial electronic payments world. Thus, the capacity of teaching these specific topics to the students was reinforced. In the same time, the team in charge of installing and taking care of the platform was created.

Beyond the technical development of this platform, the security aspects have been treated with all the constraints imposed by the banking field. As a first example, it has been established that the "banking" cards issued by the platform can be used only on ATM and POS of the platform. Another example, we do use any real banknotes in ATM, but we used fake ones that embed some security elements controlled by the ATM. An example of such banknotes is presented in Figure 3.

The first bricks that have been installed are:

- Smart cards ;

- $\quad$ Points of Interaction (POS, ATM...);

- $\quad$ Front End ;

- $\quad$ Back End ;

- Interbank Networks ;

- Safety elements.

Each brick is under the responsibility of one faculty, who becomes in fact the privileged contact at the same with the industrial company providing the equipment and for students. Due to these privileged relations developed between the school and the industrial companies, the discussions and the transmission of knowledge towards teachers and students are facilitated.

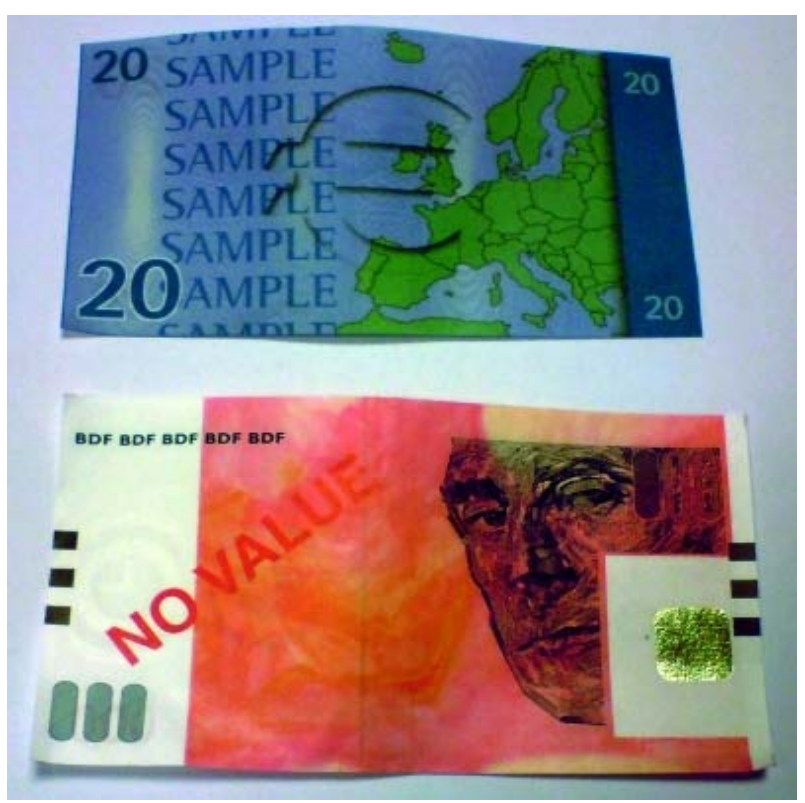

Figure 3: Example of faked banknotes used in the platform 


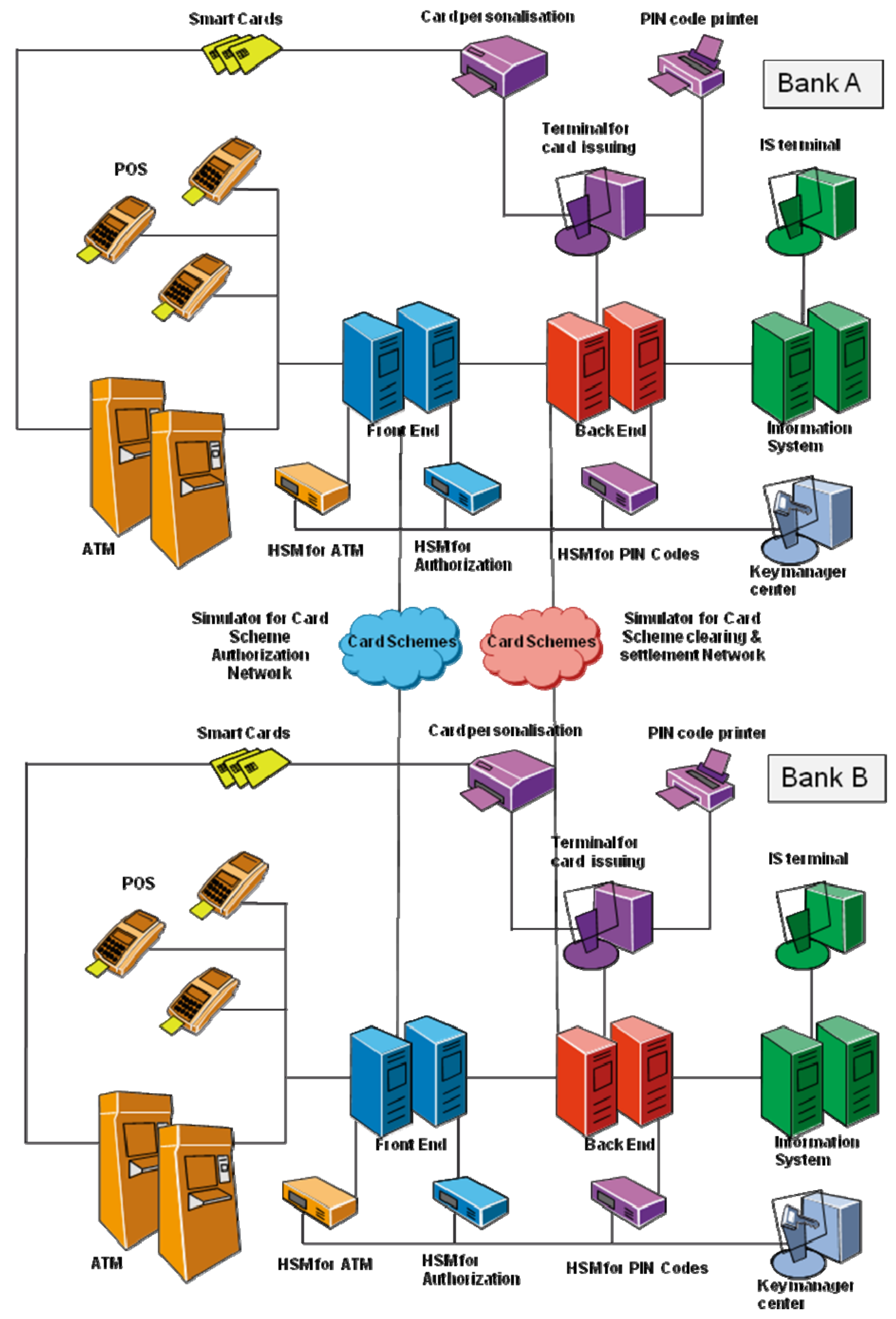

Figure 4. Diagram of the platform 


\section{COLLABORATION RESULTS}

We present in this section through the different actors that are involved in the development and use of this platform some quantitative indicators on the success of this collaboration through this technical platform.

\subsection{Training}

The student integration on the platform is part of the project. Indeed, the educational electronic payment platform is in essence dedicated to pedagogy. Thus, it appeared essential to us to associate the future users as soon as possible.

The distribution of the roles can be organized in the following way:

- Companies bring their tools to be embedded in the platform and their skills that they supply to students and teachers through training sessions ;

- Students attend those trainings, and exploit their own skills in taking actively to the platform installation ;

- The teaching team coordinates projects and tutors the students.

If the role of the industrial partners in the platform project was obvious from the beginning, the roles of the students and the teachers clearly appeared only during the project.. A project pedagogy found its place in a natural way as well among the teachers than the students.

For students and researchers involved in the projects, under the supervision of the teaching team, the preliminary studies are very interesting:

- Study of the security issues related to an environment completely conform with the banking standards but that should not in any case interfere with the real payment environments ;

- Technical and functional studies of the interfaces to be developed between bricks acquired by the school;

- Study of the needs for a banking information system, and its development.

These problems, not easily accessible during theoretical courses and practical work sessions, allow the students to face real situations. First of all, disorientated in front of the diversity of suggested subjects, they progressed little by little by asking questions or by seeking missing information at the companies. The existence of this platform has naturally opened the door to new and original experiments for the student engineers. Beyond practicing sessions, it is the way of teaching which can evolve to be closest to the companies needs.

Available since September 2006, the platform has been already exploited by the student engineers, the researchers and the industrial partners. A large part of students have carried out projects, complementary to the courses, and have faced concrete and complex problems. Followed by the teaching team, the students became actors of their own training. The carried out projects came to complete the existing platform:

- Interfacing the platform with new points of interaction;

- Modifying the platform parameters for new card types;

- Developing new modules in the bank Information System...

Actually, 10 projects are proposed to students as for example, study of an EMV transaction or study of a HSM.

Following the requests of its industrial partners, the ENSICAEN have decided in 2002 to create, in addition to the existing training, a new shared time training between the school and the industrial company. The industrial partners use the platform to train to electronic payments some of their employees in a specific Master;

Today 180 students per year are trained on the platform. Figure 5 shows the evolution of the number of trained students in the e-banking.

\subsection{Industrial partners}

The industrial partners of the platform are interested in three main usages:

- The possibility to test evolutions of their equipments on a real industrial platform ;

- The use of the environment to create relationships between them, the research laboratory and the students around R\&D programs (international, national or local) ;

- The training of their own staff, using this training platform. 


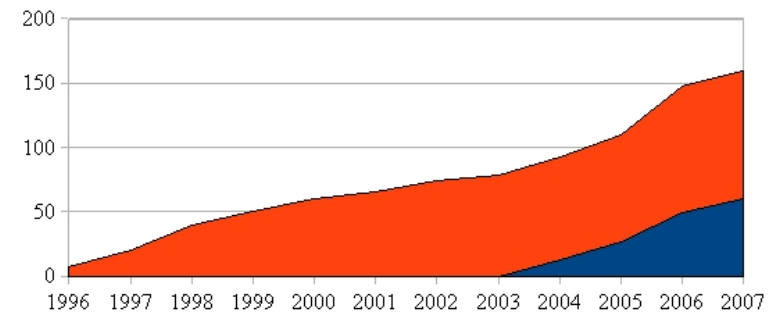

Figure 5. Evolution of the number of trained students in e-banking (in red: classical training, in blue: shared time training)

The 96 industrial partners of ENSICAEN which work in the electronic payment field and the 15 industrial partners which have participated to the platform construction, have already realized 55 test studies or development using a part or the totality of the platform. The cost of the different elements that have been provided for the platform by industrial partners is about $3 \mathrm{M} \$$.

\subsection{Research}

Lots of research programs are actually in progress using the platform. For the researchers, the platform is a very good field of experimentation:

- The use of real equipments compared to the use of simulator ;

- The proximity of industrial partners ;

- The facility to use cryptographic tools and networks to test new algorithms and architectures.

The possibilities created by this platform, have already allowed the researchers to participate to four French national research programs:

- MotesPay: a trial of payment with NFC mobile phone dual chip;

- Sopas: the aim of this project is to develop a common, low-cost authentication and secure payment solution for electronic commerce;

- Vacam: a study which the aim is to include an EMV payment application in a mobile phone SIM;

- $\mathrm{FC}^{2}:$ a research on trust circles in a banking environment;

and one international research program:

- SmartTouch: (ITEA project), a trial on the use of NFC mobile phone in any applications.

As indicator, all the projects with industrial partners brought in 2007, $850 \mathrm{~K} \$$ to the research laboratory.

\section{CONCLUSIONS AND PERSPECTIVES}

The development of this platform should not be regarded as an end. Indeed, if it is today compliant to industrial reality, and if it is a valuable teaching help, it should quickly become obsolete with the technological developments and the evolutions of services due to the market. This is the reason why a permanent survey must take place, based on the future needs, identified by the industrial partners of the platform, but also according to the progress made by university research in the related fields.

For the next two years, the different partners have identified the SEPA project as a major change in the European environment. The SEPA is a project founded by the EPC (the Council of the European Payments) and the ECB (European central bank).

The purpose of the SEPA is to set up a payment architecture allowing all the organizations and private individuals of the European zone unified to carry out payments within this zone, and that with all the advantages of a domestic payment (speed, low cost and safety of the transaction). This initiative is justified with an economic aim. Indeed, the strong costs of the European country-to-country transactions put a curb on the development of a European banking market. And in particular, it did not allow a non distorted and free competition as Europe Council recommends it. In a long term, there will be no more distinction between national payments and cross border payments. The working program will proceed from January 1, 2008 to December 31, 2010, end of deployment of SEPA in all Europe.

The main changes compared to the previous situation will be the generalization of smartcards use (that are EMV compliant) and the replacement of the TLV messages (protocol ISO 8583), by XML messages (protocol UNIFI ISO 20022) for all exchanges.

In order to prepare the platform to face that new challenge, many developments have already been decided. This phase started in November 2007, and consists in adding new functionalities. It will not only maintain the platform on a high level technology compared to the ones used in real banking, but will also allow the students to study new SEPA orientations. Formed on such an environment, engineers and researchers will have one step in advance (before graduating) on the market, and will be more capable to update the banking systems.

Five great evolutions (see Figure 6) have been identified in addition to the specific SEPA changes, and have been gradually integrated into the platform by new students:

- New points of interaction: If the banking terminals evolved little during the 10 last years, this evolution 
is accelerating and implies now the set of new payment terminals;

- RFID applications: Contactless payments are much more practical for consumers and are particularly adapted in purchase environments where the speed is essential, like in fast food, gas station, small trade supermarkets and cinemas. They also offer new cards payment possibilities in unusual purchase environments, like gas tolls;

- NFC technology: The NFC (Near Field Communication) technology of communication embedded in mobile phones permits to exchange data and to carry out transactions. The mobile phone becomes: transport tickets, access badge, payment system,...

- Biometrics: Biometric authentication is a possible solution to secure and to facilitate the authentication for the user.

- In electronic money, all cryptographic treatments [7] are delegated to an external system with protected case and well protected software called HSM. These protected enclosures are modifiable only by the manufacturer and evolve only following normative or regulatory recommendations. In order to anticipate the normalization, the specialized companies propose to provide us HSM in which a part at least of the software could be written in Java language in order to test cryptographic algorithms.

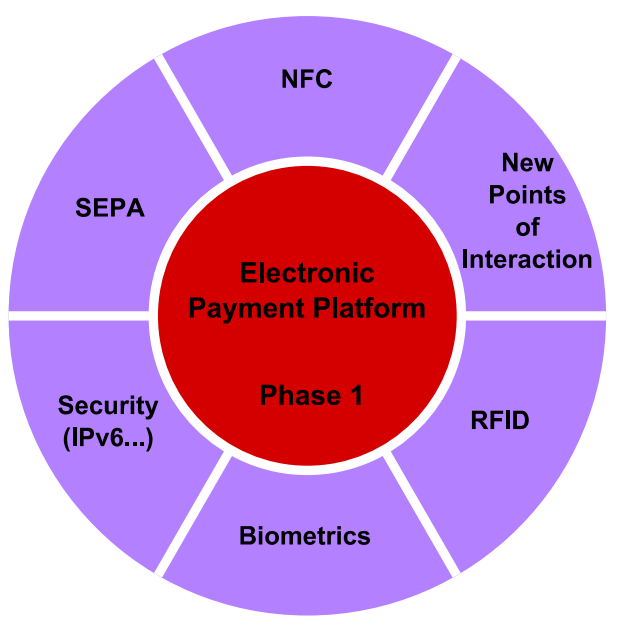

Figure 6. The new functionalities

To conclude, we can say that beyond the simple technical implementation, the learning and researching electronic payment platform is the demonstration that industrial companies, research laboratory and high schools may find a common approach:

- The school can gain a great tool to evolve pedagogy by completely implying the students in their education and by making them actors of the evolution of the tool itself.

- The research laboratory can benefit of a very high level tool for experimentation;

- The companies, in exchange of an investment in hardware, software and training sessions, can be active in the students training and secure a breeding ground of future highly qualified engineers.

\section{REFERENCES}

[1] http://www.monetique.ensicaen.fr/

[2] http://www.pole-tes.fr/

[3] http://www.dri.ensicaen.fr/sopas

[4] Pfitzmann, A., B. Pfitzmann, M. Schunter, and M. Waidner, Trusting Mobile User Devices and Security Modules, Computer, Feb. 1997, pp. 61-68.

[5] Schneier, B., APPLIED CRYPTOGRAPHY, John Wiley \& Sons, New York, 1996.

[6] Menezes, A.J., P.C. van Oorschot, and S.A. Vanstone HANDBOOK OF APPLIED CRYPTOGRAPHY, CRC Press, Boca Raton, Fla., 1997.

[7] Anderson, R., "Why Cryptosystems Fail," Communication of the ACM, Nov. 1994, pp. 32-41; ftp://ftp.cl.cam.ac.uk/users/ rja14/wcf.ps.gz

[8] Bürk, H. and A. Pfitzmann, Digital Payment Systems Enabling Security and Unobservability, Computers \& Security, Aug. 1989, pp. 399-416; http://www.semper.org/sirene/publ/BuePf_89.ps.gz

[9] Chaum, D., "Privacy Protected Payments Unconditional Payer and/or Payee Untraceability," in Smart Card 2000, North-Holland, Amsterdam, 1989, pp. 69-93.

[10] Brands, S., Untraceable Off-line Cash in Wallet with Observers, Lecture Notes in Computer Science 773, 1994, pp. 302-318.

[11] Asokan, N., P.A. Janson, M. Steiner, and M. Waidner, State of art in electronic payment systems, Computer, September 1997

[12] EMV 2000 specifications can be found at http://www.emvco.com/specifications.cfm

[13] European Central Bank, "Towards a single Euro payments area", technical Report, 2006, 
URL:http://www.ecb.int/pub/pdf/other/singleeuropaymen tsarea200602en.pdf

\section{ACKNOWLEDGMENTS}

Authors would like to thank Industrial partners, the Basse-Normandie Region, European Union Structural Funds (FSE: Fond Social Européen) and the Chamber of Commerce and Industry of Caen for the financial support of this work. 